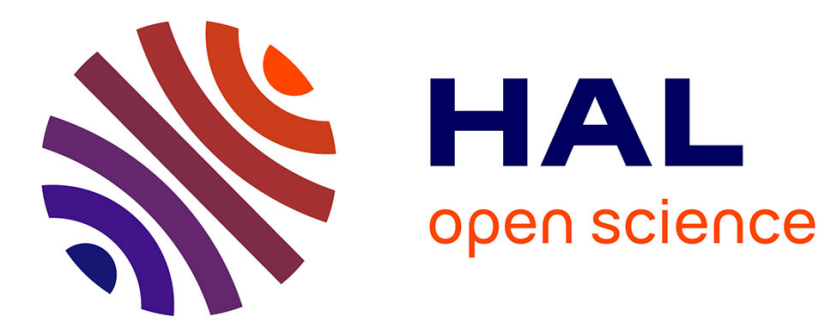

\title{
A real-time observer for UAV's brushless motors
}

Mohamad Koteich, Thierry Lemoing, Alexandre Janot, François Defaÿ

\section{To cite this version:}

Mohamad Koteich, Thierry Lemoing, Alexandre Janot, François Defaÿ. A real-time observer for UAV's brushless motors. ECMSM 2013, Jun 2013, Toulouse, France. pp.1-5, 10.1109/ECMSM.2013.6648964 . hal-00880592

HAL Id: hal-00880592

https://hal-centralesupelec.archives-ouvertes.fr/hal-00880592

Submitted on 6 Nov 2013

HAL is a multi-disciplinary open access archive for the deposit and dissemination of scientific research documents, whether they are published or not. The documents may come from teaching and research institutions in France or abroad, or from public or private research centers.
L'archive ouverte pluridisciplinaire HAL, est destinée au dépôt et à la diffusion de documents scientifiques de niveau recherche, publiés ou non, émanant des établissements d'enseignement et de recherche français ou étrangers, des laboratoires publics ou privés. 


\title{
A Real-Time Observer for UAV's Brushless Motors
}

\author{
Mohamad Koteich*, Thierry Le Moing $^{\dagger}$, Alexandre Janot ${ }^{\dagger}$ and Francois Defay ${ }^{\ddagger}$ \\ ${ }^{*}$ Supélec - Ecole Supérieur d'Electricité, Département Automatique \\ 3, rue Joliot-Curie, 91192 Gif-sur-Yvette, France. E-mail: mohamad.koteich@supelec.fr \\ †Onera - French Aerospace Lab, Centre de Toulouse, Département DCSD, Unité IDCO \\ 31055 Toulouse, France. E-mails: thierry.le_moing@onera.fr, alexandre.janot@onera.fr \\ $\ddagger$ ISAE - Institut Supérieur de l'Aéronautique et de l’Espace, Département DMIA \\ 10, avenue Edouard Belin, 31055 Toulouse, France. E-mail: francois.defay@isae.fr
}

\begin{abstract}
Vector control has been widely used in control of permanent magnet synchronous motors (PMSM). This technique requires an accurate knowledge of the rotor position. In many applications, such as mini-UAV, it is not possible to install any mechanical sensor. Therefore, a sensorless technique using position observer has to be implemented in order to estimate the rotor position. In this paper, we propose a new observer for PMSM sensorless control: the position estimate is generated upon electromagnetic relations (dynamics of magnetic flux in the motor) in the two-phase stationary reference frame. The implementation of the proposed observer is not a real burden; its validity is experimentally tested and satisfactory results are obtained regarding real position (and speed set-point) tracking in different operating situations.
\end{abstract}

\section{INTRODUCTION}

Permanent Magnet Synchronous Motors (PMSMs) are receiving increased attention for drive application. Their numerous advantages such as superior torque-speed characteristics, high torque-to-inertia ratio, high efficiency, ease of control, and noiseless operation are attributes which make them more attractive than the brushed DC motors and induction motors.

The high torque-to-inertia ratio of PMSM makes it suitable for use in Unmanned Aerial Vehicle (UAV) electric propulsion systems, where weight and space are critical factors. Motor controllers, commercially available for mini-UAV, use trapezoidal sensorless control. This technique is best suited for brushless DC (BLDC) motors with trapezoidal back EMF waveform shape. The principle is to supply two motor phases at the same time with DC current, and switch between phases in a way to produce a rotating magnetic field, stepping each 60 degrees. Switching periods are calculated using back EMF zero-crossing detection. Although BLDC and PMSM motors bear similar physical appearance, they have some differences; PMSMs have a sinusoidal back EMF and require sinusoidal stator current to produce constant torque, while BLDCs have a trapezoidal back EMF and require rectangular stator current [1]. Of course, both motors can be driven with both types of currents, but this condition should be taken for better performance [2].

Experimental results at DMIA Department in ISAE Toulouse show that many brushless motors used on miniUAVs generate sinusoidal back EMF waveforms ${ }^{1}$. Thus, a

\footnotetext{
${ }^{1}$ Results are pending publication
}

sinusoidal control technique has to be applied to optimize motor operation performance. The Field-Oriented Control (FOC) is a sinusoidal vector control technique that is best suited for three-phase machines, including PMSM. This technique needs accurate knowledge of the rotor position (and speed), which is measured by certain sensors (Encoders, Resolvers or Hall Effect sensors). However, it is well known that these sensors have a great number of drawbacks: They increase size and cost of the motor, they need special mechanical arrangements for good placement, and they have a limited temperature operational range and speed. And in many applications, it is impossible to overcome some of these drawbacks. For instance, in a mini-UAV, it is not possible to use a position sensor for a brushless mini-motor that weights no more than few grams. For this, sensorless operation is of high interest. We aim to replace position sensors by position observers, based on current and voltage measurements, in order to estimate the rotor position of PMSM.

Various sensorless control techniques have been developed for Brushless DC and Brushless AC machines, and many are still in development. All the solutions proposed during the last years have both advantages and drawbacks. Reference [3] gives a state of art of sensorless techniques for both PMSM and BLDC motor. Those for PMSM are generally based on algebraic manipulation of motor equations using voltage and current measurements. In [4] and [5], different types of these observers are discussed, including two well-known nonlinear observers: Extended Kalman Filter (EKF) and Sliding Mode Observer (SMO). The major drawback of EKF is that it deals with a fourth-order non-linear state-space system, which implies a need of high performance and high cost processors. In addition, it depends on mechanical parameters (speed, inertia and load) of the motor. Detailed equations of EKF and start-up ability analysis with simulation and experiment results can be found in [6]. Reduced order EKF is proposed and validated in [7]. SMO, on the other hand, introduces chattering phenomenon, due to the coupling between discontinuous function (sign function) and observer gain. Filtering of estimated signals is needed for better performance. More details about SMO are found in [8], where an improved SMO for sensorless vector control is proposed to reduce chattering; it is based on replacing discontinuous function by a sigmoid function. Among recent sensorless techniques, a nonlinear observer was 
proposed and tested by Ortega et al. in [9] and [10], and it shows promising results.

In this work, we propose a new state observer based on flux linkage. This observer is a second (minimal) order linear system, its implementation is not a real burden, and it shows satisfactory results on mini-UAV Brushless motors. One important feature of this observer is its ability to start the motor using sensorless closed-loop control.

First, PMSM model is given (only electromagnetic equations are needed for the observer). Next, the system to be observed is written in state space representation, and then observer equations are synthesized. The validity of our observer is tested in simulation and experimentally in different operating situations. Finally we make conclusions and propose future work.

\section{UAV'S BRUSHLESS MOTOR MODELING}

The choice of a suitable model is a critical step to design the position's observer. UAV's brushless motors are specific PMSM motors. Their size and their carracteristics (number of poles, conductor diameter) induce a different modelling compared to conventional brushless motors. Many experiments carried in the DMIA labs on motors of different size and different providers ( $3 \mathrm{~g}$ to $70 \mathrm{~g}$ ) allow us to specify that this kind of motors has a sinusoidal electromecanical force. The size of the motors (principally the length of rotors) induces some limitations compared to classical model (the border effect can't be neglected). In this paper, classical PMSM model will be considered in a first approach.. The proposed observer is based on electromagnetic equations in the stationary reference frame $\alpha \beta$. Equations in this reference frame are calculated from 3 -phase equations using Clarke Transformation:

$$
\left[X_{\alpha \beta}\right]=C_{23}\left[X_{a b c}\right]
$$

where

$$
C_{23}=\frac{2}{3}\left[\begin{array}{ccc}
1 & -\frac{1}{2} & -\frac{1}{2} \\
0 & \frac{\sqrt{3}}{2} & -\frac{\sqrt{3}}{2}
\end{array}\right]
$$

Flux equations in $\alpha \beta$ reference frame are given by:

$$
\begin{aligned}
\phi_{\alpha} & =L i_{\alpha}+\phi_{r} \cos \theta_{e} \\
\phi_{\beta} & =L i_{\beta}+\phi_{r} \sin \theta_{e}
\end{aligned}
$$

Ohm's law can be written as following:

$$
\begin{aligned}
v_{\alpha} & =R i_{\alpha}+\frac{d \phi_{\alpha}}{d t} \\
& =R i_{\alpha}+L \frac{d i_{\alpha}}{d t}-p \phi_{r} \Omega \sin \theta_{e} \\
v_{\beta} & =R i_{\beta}+\frac{d \phi_{\beta}}{d t} \\
& =R i_{\beta}+L \frac{d i_{\beta}}{d t}+p \phi_{r} \Omega \cos \theta_{e}
\end{aligned}
$$

The produced torque is given by:

$$
T_{e}=\frac{3}{2} p \phi_{r}\left[i_{\beta} \cos \theta_{e}-i_{\alpha} \sin \theta_{e}\right]
$$

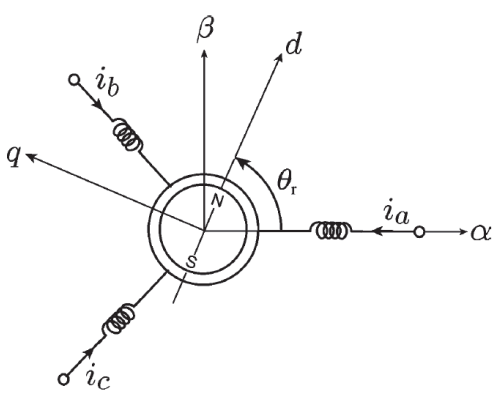

Fig. 1. Schematic diagram of the PMSM

where $\phi_{\alpha}$ and $\phi_{\beta}$ are flux linkage, $i_{\alpha}$ and $i_{\beta}$ are stator currents, $v_{\alpha}$ and $v_{\beta}$ are motor terminal voltage, $\theta_{e}$ is the rotor electrical position (to be estimated), $\Omega$ is the mechanical speed of the motor, $p$ is the number of rotor pole pairs, $T_{e}$ is the electromagnetic torque, $\phi_{r}$ is the permanent magnet flux linkage, and $R$ and $L$ are respectively stator resistance and cyclic inductance the stationary reference frame $\alpha \beta$. Note that since the motor is assumed unsaturated non-salient PMSM, stator inductance is constant and independent of rotor position.

\section{The Proposed ObSERVER}

In this section, we propose a new position observer. The originality of our approach is the choice of the system?s output.

\section{A. State Space Representation}

State variables used to construct the observer are flux linkage through two fictitious coils, $\phi_{\alpha}$ and $\phi_{\beta}$, which are the projections of three-phase fluxes on the two-phase stationary reference frame $\alpha \beta$ using Clarke transformation. The state vector is:

$$
x=\left(\begin{array}{l}
\phi_{\alpha} \\
\phi_{\beta}
\end{array}\right)
$$

Using equations (3) and (4), electrical position can be calculated as follows:

$$
\theta_{e}=\arctan \left[\frac{\phi_{\beta}-L i_{\beta}}{\phi_{\alpha}-L i_{\alpha}}\right]
$$

Stator inductance $L$ is considered to be known, $i_{\alpha}$ and $i_{\beta}$ are measured. The estimation of $\theta_{e}$ is based on the estimation of state vector $x$.

1) The state equations: Dynamics of flux linkage can be obtained from equations (5) and (6):

$$
\begin{aligned}
\dot{x} & =\left(\begin{array}{c}
\frac{d \phi_{\alpha}}{d t} \\
\frac{d \phi_{\beta}}{d t}
\end{array}\right)=\left(\begin{array}{c}
v_{\alpha}-R i_{\alpha} \\
v_{\beta}-R i_{\beta}
\end{array}\right) \\
& =A x+B u
\end{aligned}
$$

Note that voltages and currents are observer inputs, and the stator resistance $R$ is considered to be known. Let:

$$
u=\left(\begin{array}{c}
v_{\alpha}-R i_{\alpha} \\
v_{\beta}-R i_{\beta}
\end{array}\right)
$$

Then $A$ is null and $B=[1,1]^{T}$. 
2) Output equations: The choice of the system output is very important because this output will be compared to the estimated one called observer output. The difference between actual and estiamted outputs will be used in observer's equations as a correction term of state variables estimates. To choose a suitable output, two facts must be taken into account:

- first: this output should be measurable;

- second: the output should be able to be estimated using the system state variables in order to design the observer. The output that we have chosen for our observer is defined as:

$$
y=\left(\begin{array}{c}
L i_{\alpha} \\
L i_{\beta}
\end{array}\right)
$$

This output (stator currents in $\alpha \beta$ reference frame) is measurable, and it can be estimated using (3) and (4), we get:

$$
\begin{aligned}
\hat{y} & =\left(\begin{array}{l}
L \hat{i}_{\alpha} \\
L \hat{i}_{\beta}
\end{array}\right)=\left(\begin{array}{l}
\hat{\phi}_{\alpha}-\phi_{r} \cos \hat{\theta}_{e} \\
\hat{\phi}_{\beta}-\phi_{r} \sin \hat{\theta}_{e}
\end{array}\right) \\
& =C \hat{x}+f\left(\hat{\theta}_{e}\right)
\end{aligned}
$$

where $C$ is the identity matrix $I_{2 \times 2} . f\left(\hat{\theta}_{e}\right)$ is a non-linear term that depends on permanent magnet flux and rotor position. This dependency is not desirable; it introduces non-linearity due to the trigonometric functions.

\section{B. State Observer Equations}

The proposed observer is a standard state observer that can be represented as following:

$$
\begin{aligned}
\frac{d \hat{x}}{d t} & =A \hat{x}+B u+K(y-\hat{y}) \\
\hat{y} & =C \hat{x}+f\left(\hat{\theta}_{e}\right)
\end{aligned}
$$

Combining (11) and (12) gives:

$$
\frac{d \hat{x}}{d t}=A \hat{x}+B u+K(y-\hat{y})
$$

We apply equation (13) on the system defined by (7), (9) and (10) in the above subsection, we get:

$$
\begin{aligned}
\frac{d \hat{\phi}_{\alpha}}{d t} & =v_{\alpha}-R i_{\alpha}+K_{1}\left[L i_{\alpha}-\left(\hat{\phi}_{\alpha}-\phi_{r} \cos \hat{\theta}_{e}\right)\right] \\
\frac{d \hat{\phi}_{\beta}}{d t} & =v_{\beta}-R i_{\beta}+K_{2}\left[L i_{\beta}-\left(\hat{\phi}_{\beta}-\phi_{r} \sin \hat{\theta}_{e}\right)\right]
\end{aligned}
$$

we finally get the following observer equations:

$$
\begin{aligned}
\frac{d \hat{\phi}_{\alpha}}{d t} & =-K_{1} \hat{\phi}_{\alpha}+v_{\alpha}-R i_{\alpha}+K_{1}\left(L i_{\alpha}+\phi_{r} \cos \hat{\theta}_{e}\right) \\
\frac{d \hat{\phi}_{\beta}}{d t} & =-K_{2} \hat{\phi}_{\beta}+v_{\beta}-R i_{\beta}+K_{2}\left(L i_{\beta}+\phi_{r} \sin \hat{\theta}_{e}\right)
\end{aligned}
$$

\section{Position and speed estimation}

Position and speed estimates, based on flux linkage estimated by the proposed observer, are given by:

$$
\begin{aligned}
\hat{\theta}_{e} & =\arctan \left[\frac{\hat{\phi}_{\beta}-L i_{\beta}}{\hat{\phi}_{\alpha}-L i_{\alpha}}\right] \\
\hat{\Omega} & =p \frac{d \hat{\theta}_{e}}{d t}
\end{aligned}
$$

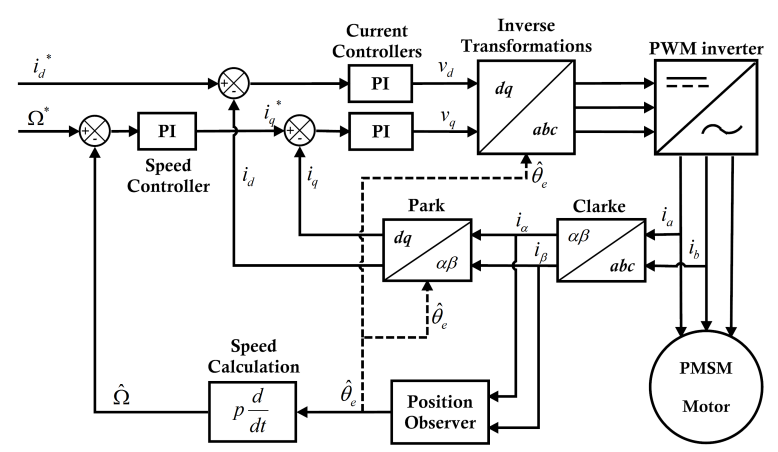

Fig. 2. Sensorless FOC block diagram

Figure 2 shows the sensorless FOC scheme used for PMSM. Measured and estimated signals are also shown.

\section{Observer Tuning}

The proposed observer can be tuned by means of observer gain $K$ :

$$
K=\left(\begin{array}{l}
K_{1} \\
K_{2}
\end{array}\right)
$$

Observed system is flux linkage, whose dynamics is imposed by current closed-loop dynamics in the $d q$ synchronous reference frame. On the other hand, observer dynamics has to be faster than the electrical system one (typically 10 times faster), respecting the principle of separation of estimation and control. Hence, the observer has to be tuned in a way to fulfill the above constraints, which implies that observer gains have to be calculated to obtain an observer response time 10 times lower than current closed-loop response time.

\section{EXPERIMENTAL RESULTS}

Experiments were performed on a mini-UAV Brushless motor, which is the ROXXY BL Outrunner 2824/34, that drives a GWS 8x4.5 type 2-blade propeller, using DRV8312C2 DSP board. The experimental system assembly is shown in the figure 3. A Quadratic Encoder Pulse (QEP) sensor is used to merely detect the rotor position wich is compared with the estimated rotor position. Two motor phase currents are sensed, rescaled, and converted to digital values by onchip ADC with 12-bit resolution. The PMSM is supplied by a three phase voltage source PWM inverter. The PWM gate firing signals from the desired phase voltage commands are generated by means of the space vector modulation technique. The sampling period of the control system is set at $50 \mu \mathrm{s}$. The motor parameters are given in Table 1 .

\section{A. Open-loop start-up}

One of the important problems, that sensorless techniques face, is sensorless closed-loop motor start-up. To avoid this problem we use an open-loop start-up procedure, in order to start the motor and turn it at a certain speed, and then we switch to closed-loop sensorless control.

Open-loop motor start-up procedure (see figure 4) consists of closing current control loops, opening speed control loop, 


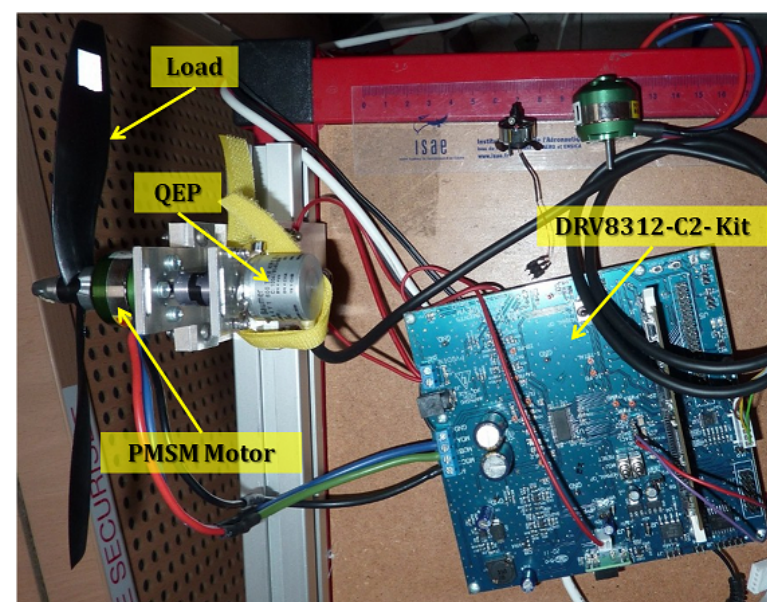

Fig. 3. Experimenal system

TABLE I

PARAMETERS OF THE MINI-UAV PMSM USED FOR EXPERIMENTS

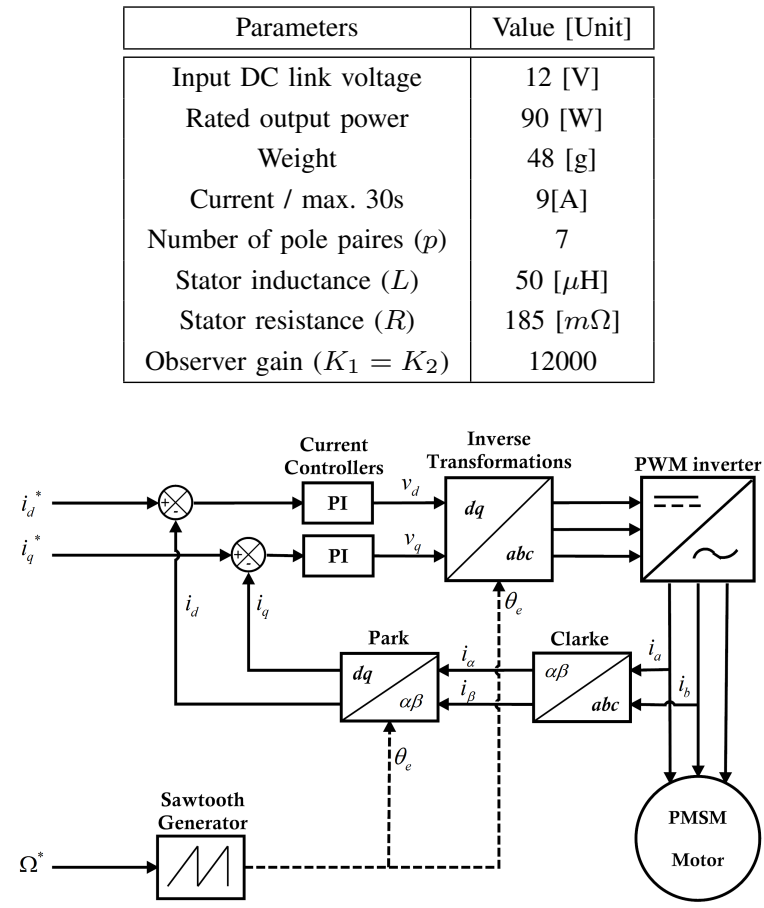

Fig. 4. Open-loop operation block diagram

applying a zero set point to $i_{d}$, and applying a set point to $i_{q}$ in a way to impose a torque in consistency with motor speed, wich is imposed by electrical position $\theta_{e}$ applied to Park and inverse Park transformations. $\theta_{e}$ is generated using a ramp generator at the desired rotation frequency. However, open-loop start-up is not desirable, because if torque-speed couple is not chosen correctly, it can lead to abnormal motor operation (vibration, heating up, etc.). But in absence of sensorless closed-loop start-up techniques, open-loop cannot be avoidable.

The observer estimation should converge to real position before switching to closed-loop control. Figure 5 shows the

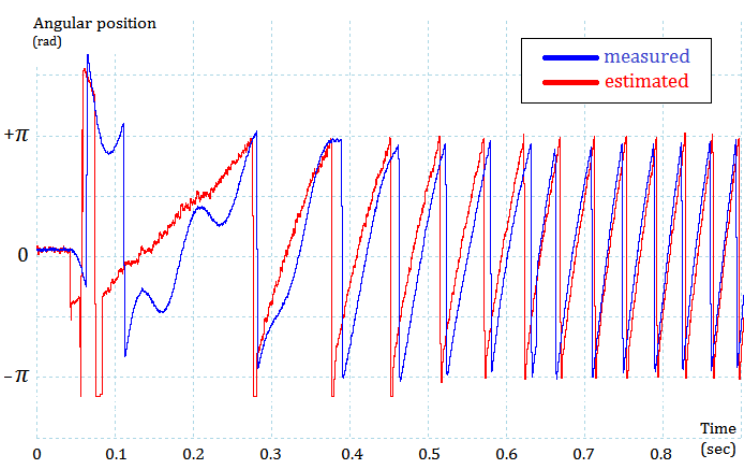

Fig. 5. Measured and estimated position for open-loop start-up

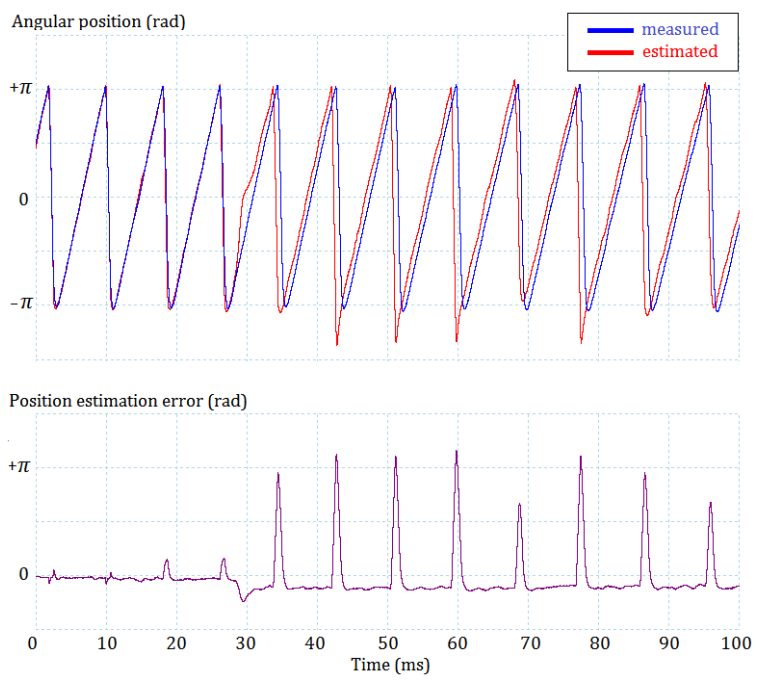

Fig. 6. Measured and estimated position at $1000 \mathrm{rpm}$ during switching from open-loop to closed-loop control at $30 \mathrm{~ms}$

real and the estimated position at open-loop start-up. Imposed speed is $1000 \mathrm{rpm}$, and when this speed is reached control switching is done. Figure 6 shows the behavior of the rotor when switching to sensorless closed-loop control using the proposed observer (switching instant is at $30 \mathrm{~ms}$ ). Note that the estimation error is near zero, and the peaks that appear on the error correspond to the small delay between switching instants (from $+\pi$ to $-\pi$ ) of estimated and measured position. Observer gains used are $K_{1}=K_{2}=12000$.

\section{B. Sensorless closed-loop start-up}

The motor start-up shown in the previous test is not desirable, and neither is control switching. We are interested in an observer that can start the motor without needing them. The proposed observer shows good performance for sensorless closed-loop start-up.

The speed PI controller is tuned in a way to have a $100 \mathrm{~Hz}$ bandwidth, and $700 \mathrm{~Hz}$ bandwidth is chosen for the currents PI controllers.

Figure 7 shows the measured and the estimated position at sensorless closed-loop start-up (speed set point is $1000 \mathrm{rpm}$ ). The measured and the estimated speed behavior when starting 

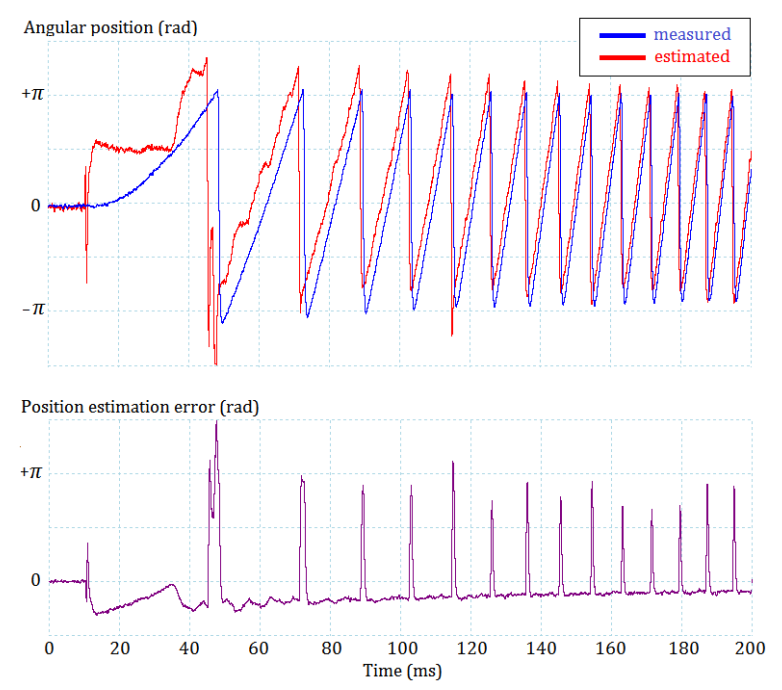

Fig. 7. Measured and estimated position for sensorless closed-loop start-up

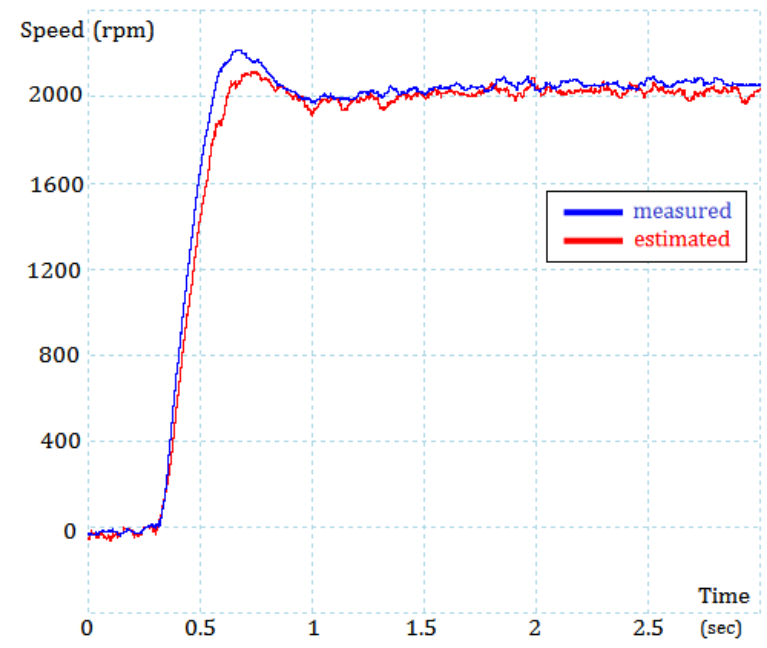

Fig. 8. Measured and estimated speed for sensorless closed-loop start-up

the motor is shown in figure 8 (speed set point is $2000 \mathrm{rpm}$ ), we notice that the speed response time $\left(t_{r} \simeq 0.3\right.$ seconds $)$ is acceptable, and in coherence with the speed PI bandwidth (100 Hz).

In all previous tests, where the proposed observer is inserted, the sensorless FOC shows satisfactory results, even though the load (propeller) is not well balanced in our experimental configuration, which appears in the speed steady state small fluctuations.

\section{CONCLusion}

In this paper, a new observer for PMSM sensorless control has been presented. Compared with classical observers, this observer presents many advantages:

- it is a minimal order observer (second order) that depends on electrical dynamics only;

- its implementation is not a real burden;
- it is able to start the motor using sensorless closed-loop control;

- gain tuning is done with respect to current closed-loop response time.

The proposed observer has been tested on a mini-UAV motor and it has shown good performance regarding position and speed estimation for sensorless FOC. These promising results motivate us to test it on different motors. In addition, a thorough study of its characteristics has to be done (especially the convergence of the error) taking into account the perturbed term in order to estimate $\theta_{e}$.

\section{REFERENCES}

[1] P. Pillay and R.T. Krishnan, "Modeling of Permanent Magnet Motor Drives," IEEE Trans. On Industrial Electronics, vol. 35, no. 4, Nov. 1988

[2] B. Akin, M. Bhardwaj and J. Warriner "Sensorless Trapezoidal Control of BLDC Motors," Texas Instruments Document, ver. 1, Apr 2011.

[3] D. Montesinos, S. Galceran, F. Blaabjerg, A. Sudria, and O. Gomis, "Sensorless control of PM synchronous motors and brushless DC motors. An overview and evaluation," EPE 2005 - Dresden.

[4] M. Fadel, R. Ruelland, G. Gateau, J.C. Hapiot, P. Brodeau and J.P. Carayon "Commande sans capteur mcanique des actionneurs embarqus," J3eA, Journal sur l'enseignement des sciences et technologies de l'information et des systmes, volume 4, Hors-Srie 1, 9 (2005).

[5] L. Yongdong and Z. Hao "Sensorless Control of Permanent Magnet Synchronous Motor - A Survey," IEEE Vehicle Power and Propulsion Conference (VPPC), September 3-5, 2008, Harbin, China.

[6] Z. Zheng, Y. Li, M. Fadel "Sensorless Control of PMSM Based on Extended Kalman Filter," EPE 2007-Aalborg.

[7] J.S. Jang "Parallel reduced-order Extended Kalman Filter for PMSM sensorless drives," Industrial Electronics, 2008. IECON 2008. 34th Annual Conference of IEEE.

[8] K. Paponpen and M. Konghirun "An Improved Sliding Mode Observer for Speed Sensorless Vector Control Drive of PMSM," IPEMC 2006.

[9] R. Ortega, L. Praly, A. Astolfi, J. Lee, and K. Nam "Estimation of Rotor Position and Speed of Permanent Magnet Synchronous Motors With Guaranteed Stability" IEEE TCST.2010.2047396.

[10] J. Lee, J. Hong, K. Nam, R. Ortega, L. Praly and A. Astolfi "Sensorless Control of Surface-Mount Permanent-Magnet Synchronous Motors Based on a Nonlinear Observer" IEEE Transactions on Power Electronics, vol. 25 , no. 2, february 2010 . 